(2) Open Access Full Text Article

\title{
Letter to the editor: dexamethasone intravitreal implant in the treatment of diabetic macular edema
}

This article was published in the following Dove Press journal:

Clinical Ophthalmology

16 November 2015

Number of times this article has been viewed

John Hall

Alimera Sciences Ltd., Aldershot, Hampshire, UK

\section{Dear editor}

I read "Dexamethasone intravitreal implant in the treatment of diabetic macular edema" published July 2015 by Dugel et al. ${ }^{1}$ This article is very interesting in terms of providing an outline of the role of inflammation in the pathogenesis of diabetic macular edema and explaining the value of corticosteroids in the treatment of diabetic macular edema.

However, I would like to draw your attention to the data presented for ILUVIEN ${ }^{\circledR}$ (fluocinolone acetonide; FAc) in Table 2, which has been presented incorrectly and does not reflect the approved product and dose in Europe. ILUVIEN is indicated in Europe for the treatment of vision impairment associated with chronic diabetic macular edema, considered insufficiently responsive to available therapies ${ }^{2}$ and is approved in Austria, Belgium, Czech Republic, Denmark, Finland, France, Germany, Ireland, Italy, Luxembourg, the Netherlands, Norway, Poland, Portugal, Spain, Sweden, and the United Kingdom. ILUVIEN was launched in the United Kingdom in April 2013, Germany in May 2013, and Portugal in January 2015. ${ }^{3}$

ILUVIEN contains $190 \mu \mathrm{g}$ of FAc and delivers $0.2 \mu \mathrm{g}$ of FAc per day. Dugel et al ${ }^{1}$ presented the data for the $0.5 \mu \mathrm{g}$ of FAc per day, which was studied in the FAME studies but is not the approved dose in Europe. This needs to be explained to the reader as the data that are relevant to the currently marketed product are those of the $0.2 \mu \mathrm{g}$ of FAc

\begin{tabular}{ll}
\hline Parameter & ILUVIEN \\
\hline Therapeutic indication & For the treatment of vision impairment associated with \\
& chronic DME, considered insufficiently responsive to available
\end{tabular}

Active drug

Formulation

Dose

Duration of action (months)
License approval

a. European countries where an ILUVIEN license has been granted

b. European countries where ILUVIEN has been launched chronic DME, considered insufficiently responsive to available therapies $^{2}$

Fluocinolone acetonide (FAc) ${ }^{2}$

Non-biodegradable implant (polyimide tube) ${ }^{2}$

$190 \mu \mathrm{g}$ of FAc with a daily release rate of $0.2 \mu \mathrm{g}^{2}$

Up to 36 months. This is underpinned by a pharmacokinetic study in human eyes, which showed that following a single intravitreal injection of ILUVIEN, there was a stable delivery of $0.2 \mu \mathrm{g}$ of FAc per day that was sustained and therefore detectable after 36 months. ${ }^{2,4}$ This is complemented by efficacy data that show mean improvements in BCVA and central foveal thickness, from baseline levels, for up to 36 months ${ }^{2,5}$ Status:

a. Austria, Belgium, Czech Republic, Denmark, Finland, France, Germany, Ireland, Italy, Luxembourg, the Netherlands, Norway, Poland, Portugal, Spain, Sweden, the United Kingdom ${ }^{3}$

b. United Kingdom, April 2013; Germany, May 2013; and Portugal, January $2015^{3}$ 
(Continued)

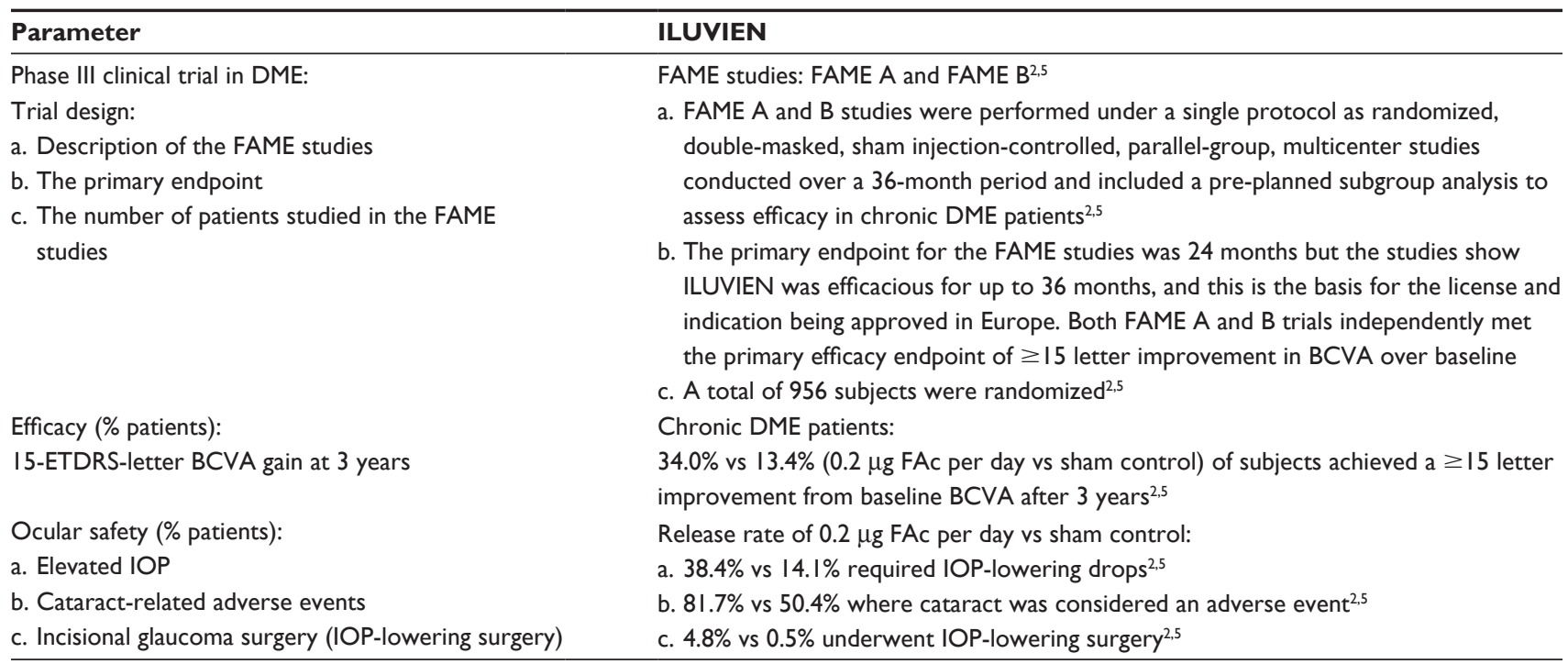

Abbreviations: DME, diabetic macular edema; BCVA, best-corrected visual acuity; FAME, Fluocinolone Acetonide for Diabetic Macular Edema; ETDRS, Early Treatment Diabetic Retinopathy Study; IOP, intraocular pressure.

per day release rate. ${ }^{2,4}$ Thus, Table 2 presented in Dugel et al has been amended to reflect the data for ILUVIEN.

A number of papers have been published on the pharmacokinetic, ${ }^{4}$ safety, and efficacy of ILUVIEN,${ }^{5}$ and the reader can access the summary of product characteristics for ILUVIEN online. ${ }^{2}$

\section{Disclosure}

The author reports no conflicts of interest in this communication.

\section{References}

1. Dugel PU, Bandello F, Loewenstein A. Dexamethasone intravitreal implant in the treatment of diabetic macular edema. Clin Ophthalmol. 2015;9:1321-1335.
2. Electronics Medicine Compendium. Summary of Product Characteristics for ILUVIEN 190 micrograms intravitreal implant in applicator. Available from: https://www.medicines.org.uk/emc/medicine/27636. Accessed August 4, 2015.

3. Alimera Sciences Press Releases. Alpharetta: Alimera Sciences, Inc. Available from: http://investor.alimerasciences.com/releases.cfm. Accessed August 4, 2015.

4. Campochiaro PA, Nguyen QD, Hafiz G, et al; FAMOUS Study Group. Aqueous levels of fluocinolone acetonide after administration of fluocinolone acetonide inserts or fluocinolone acetonide implants. Ophthalmology. 2013;120(3):583-587.

5. Campochiaro PA, Brown DM, Pearson A, et al; FAME Study Group. Sustained delivery fluocinolone acetonide vitreous inserts provide benefit for at least 3 years in patients with diabetic macular edema. Ophthalmology. 2012;119(10):2125-2132. 


\section{Authors' reply \\ Pravin U Dugel ${ }^{1,2}$ \\ Francesco Bandello 3 \\ Anat Loewenstein ${ }^{4}$}

'Retinal Consultants of Arizona, Phoenix, AZ, ${ }^{2}$ Department of Ophthalmology, Keck School of Medicine, University of Southern California, Los Angeles, CA, USA; ${ }^{3}$ Department of Ophthalmology, University Vita-Salute Scientific Institute San Raffaele, Milan, Italy; ${ }^{4}$ Department of Ophthalmology, Tel Aviv Medical Center and Sackler Faculty of Medicine, Tel Aviv University, Tel Aviv, Israel

\section{Dear editor}

We would like to thank Dr Hall for his interest in our recently published review article, ${ }^{1}$ and Clinical Ophthalmology for inviting us to respond to the points raised in his letter.

It should be noted that the primary aim of our article was to review the clinical efficacy and safety of dexamethasone intravitreal implant in the treatment of diabetic macular edema; for this reason only brief mention was made of other intravitreal corticosteroid delivery systems. Comparative data were limited to a short summary (Table 2 ) of the properties of Ozurdex ${ }^{\circledR}$ (dexamethasone intravitreal implant $0.7 \mathrm{mg}$ ) and ILUVIEN ${ }^{\circledR}$ (fluocinolone acetonide intravitreal implant $190 \mu \mathrm{g})$ - the two sustained-release intravitreal corticosteroid formulations currently approved for the treatment of diabetic macular edema. The table accurately summarizes the efficacy and safety data from the published $\mathrm{MEAD}^{2}$ and $\mathrm{FAME}^{3}$ studies - all doses investigated in these Phase III trials are presented and clearly annotated in the table. In the case of the FAME study, this includes both the low-dose $(0.2 \mu \mathrm{g} /$ day $)$ and high-dose $(0.5 \mu \mathrm{g} /$ day $)$ formulations of fluocinolone acetonide intravitreal implant $190 \mu \mathrm{g}$. The data, therefore, are relevant to the product currently marketed in Europe and the United States, ILUVIEN, which releases $0.2 \mu \mathrm{g}$ of fluocinolone acetonide per day.

The content of the amended table presented by Dr Hall, based as it is on the European Summary of Product Characteristics for ILUVIEN, goes well beyond the scope and intent of our original table. Other than referring to the date of US Food and Drug Administration approval, our article avoids all mention of product licensing and labeling in the various regional markets. We feel that these marketing details would be out of place in a review of the scientific literature.

\section{Disclosure}

The authors report no conflicts of interest in this communication.

\section{References}

1. Dugel PU, Bandello F, Loewenstein A. Dexamethasone intravitreal implant in the treatment of diabetic macular edema. Clin Ophthalmol. 2015;9:1321-1335.

2. Boyer DS, Yoon YH, Belfort R Jr, et al; Ozurdex MEAD Study Group. Three-year, randomized, sham-controlled trial of dexamethasone intravitreal implant in patients with diabetic macular edema. Ophthalmology. 2014;121:1904-1914

3. Campochiaro PA, Brown DM, Pearson A, et al; FAME Study Group. Sustained delivery fluocinolone acetonide vitreous inserts provide benefit for at least 3 years in patients with diabetic macular edema. Ophthalmology. 2012;119:2125-2132.

Dove Medical Press encourages responsible, free and frank academic debate. The content of the Clinical Ophthalmology 'letters to the editor' section does not necessarily represent the views of Dove Medical Press, its officers, agents, employees, related entities or the Clinical Ophthalmology editors. While all reasonable steps have been taken to confirm the content of each letter, Dove Medical Press accepts no liability in respect of the content of any letter, nor is it responsible for the content and accuracy of any letter to the editor.

\section{Publish your work in this journal}

Clinical Ophthalmology is an international, peer-reviewed journal covering all subspecialties within ophthalmology. Key topics include: Optometry; Visual science; Pharmacology and drug therapy in eye diseases; Basic Sciences; Primary and Secondary eye care; Patient Safety and Quality of Care Improvements. This journal is indexed on

Submit your manuscript here: http://www.dovepress.com/clinical-ophthalmology-journal
PubMed Central and CAS, and is the official journal of The Society of Clinical Ophthalmology (SCO). The manuscript management system is completely online and includes a very quick and fair peer-review system, which is all easy to use. Visit http://www.dovepress.com/ testimonials.php to read real quotes from published authors. 